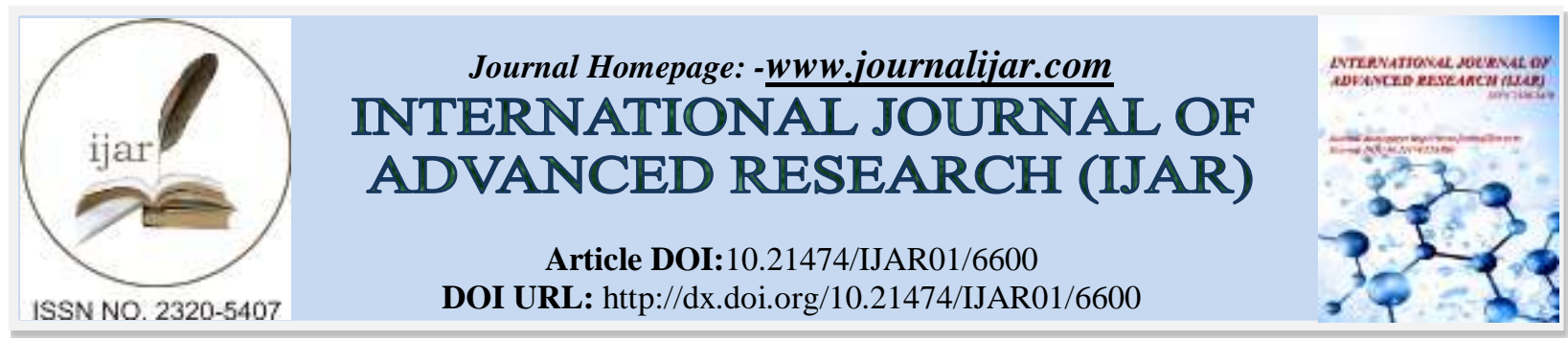

RESEARCH ARTICLE

\title{
EFFECTIVENESS OF VIDEO ASSISTED TEACHING ON SELF ASSESSMENT OF DAILY FETAL MOVEMENT COUNT(DFMC), AMONG PRIMIGRAVIDAE, IN SELECTED MATERNITY HOSPITALS AT BENGALURU.
}

Ms. Rinu Mathew.

Lecturer Krupanidhi College of Nursing, Dr. Prof Suvarna B Talwar Principal Government College of Nursing.

\section{Manuscript Info}

Manuscript History

Received: 21 December 2017

Final Accepted: 23 January 2018

Published: February 2018

\section{Abstract}

Maternal perception of fetal movement is a valuable tool for early detection of fetal compromise. Fetal movement is a reliable sign of fetal well being. These early signs of fetal movement may at first be confused as simply gas, but actually growing baby is rocking and rolling inside the belly. Fetal movement counting often called 'kick counting' represents a maneuver whereby a mother can help monitor the movements of her unborn baby by counting the number of kicks in a given time period. This is an indicator of fetal health and the novice mothers can identify and prevent the complications before the child birth. In order to educate and encourage the primigravidae to improve their knowledge regarding fetal movement counting, the study was conducted to evaluate the Effectiveness of video assisted Teaching on knowledge regarding self assessment of daily fetal movement (DFMC), among primigravidae in selected maternity hospitals at, Bengaluru. Methods: Pre-experimental design, with non probability purposive sampling method was used. Information was collected from 50 primigravidae attending antenatal OPD regarding self assessment of daily fetal movement count (DFMC) using the structured knowledge questionnaire. VAT was implemented and post-test was conducted after 7 days to find the effectiveness.

Results: Regarding effectiveness of VAT, the overall mean knowledge score in the pre-test was $31.92 \%$ and $83.58 \%$ in the post test with enhancement of $51.66 \%$ and it was significant at 5\% level. Analysis of socio-demographic variables showed significant association between age in years, occupational status, with knowledge score at 5\% level $(\mathrm{P}>0.05)$.

Interpretation And Conclusion:Overall findings showed that pre-test knowledge scores were found to be $31.92 \%$ and after VAT, knowledge of primigraviadae was enhanced by $51.66 \%$ regarding DFMC. Hence the result has proved that VAT was effective in improving the knowledge of primigravidae attending antenatal OPD regarding DFMC.

Copy Right, IJAR, 2018,. All rights reserved.

Corresponding Author:- Ms. Rinu Mathew. 


\section{Introduction:-}

"Giving birth and being born brings us into the essence of creation, where the human spirit is courageous and bold and the body, a miracle of wisdom." -Harriette Hartigan

Pregnancy is considered as a very precious event in every woman's life. It is filled with happiness, joy and surprises. Every parents hopes for a healthy baby, but sometimes become sorrowful when danger sets in either to the mother or to the fetus. Pregnancy links mother and fetus together and is the basis for regenerating the generation. Most pregnancies and with work of a live baby to a healthy mother. In high risk pregnancies the mother may sometimes escape death but fetus and neonates often become the victim ${ }^{1}$.

According to the recent statistics it estimates above $75 \%$ of the fetal death occur in the antepartum it is obvious that that limiting fetal surveillance to intrapartum period will not achieve optimal perinatal outcome. Yet for every 1000 birth the perinatal mortality is 37.7 , varies from 24.8 in Kerala to $75.5 / 1000$ in Orissa. It is higher in rural(54.4) and( 20.3)in urban, which is lower. It is estimated that 7.3 million perinatal deaths occur annually in the world and most of these in the developing countries. In India alone about 8,90,000 perinatal deaths occur annually and that of Karnataka the stillbirth rate is $20 / 1000$ deliveries, which is highest among all the other states ${ }^{2}$.

Decreased fetal movement count are present in 5\% to $15 \%$ of pregnancies and are associated with intrauterine fetal death and intra uterine growth restriction(Obstetrical and Gynecological survey-England,2008) ${ }^{3}$.

The current scientific research conference about decreased fetal movement count in Norway revealed that fetal deaths are not sudden; 50\% of unexplained stillbirths are growth restricted and, suggesting that there is time window for intervention and prevention of deaths. In recently completed "MOMS STUDY"(Maternal Observations and Memories Of Stillbirths)data from 5000 women who had stillbirth is currently being analysed. The result reveals the following , 50\% of the women reported gradual decreased fetal movement count, several days prior to the fetal death, 56\% of women reported decreased fetal movement count as the first reason to believe that the baby was not doing well. Only about $50 \%$ of women were told to do fetal kick counts by their doctors ${ }^{4}$.

FEMINA(fetal movement intervention assessment) is an ongoing International Research Collaboration to improve the pregnancy outcome. The findings reveal that women still do not get enough information on importance of fetal activity to act in such a way to protect their baby. Public relation in Norway as well as in the U.S. are on the way educating the public regarding fetal movement count ${ }^{4}$.

In June 2014WHO, UNICEF and partners issued the first ever global plan to end stillbirths by 2035 by providing high quality affordable services to all women ${ }^{5}$.

A prospective observational study was conducted in St. Martha's Hospital Bengaluru, Karnataka over a period of 13 months. It included 50 pregnant women after 32 weeks of gestation and singleton pregnancies with $<12$ fetal movements in 24 hours. They underwent a cardiotocogram(CTG) and biophysical profile test(BPP) and results were analysed statistically. A non -reactive CTG on admission was encountered in 2/50(04\%) vs 21/50(42\%); ( $<<0.001$ ) of women with reduced fetal movements at delivery. Majority 20/50(40\%) of the caesarean sections were emergency due to non reassuring CTG. Neonatal birth weight $<2500$ grams was recorded in 25/50(50\%) and $10 / 26(38.46 \%)$ had meconium staining of liquor indicating an unfavorable intra uterine environment. The study concluded although, daily fetal movement counting is subjective, with onset of maternal perception of reduced fetal movements. It is prudent to advocate close fetal monitoring even in the presence of a reactive admission CTG. Hence a timely obstetric intervention is needed ${ }^{6}$.

Discussion with the experts and review of literature helped the investigator to realize that providing a effective education on the importance of daily fetal movement count is essential to reduce the perinatal mortality and morbidity rates. During the review literature the investigator found that studies related to this in India is less, which has shown the increasing need of the study. Investigator felt effective education provides the primigravidae to have a good time to be spent for the child before its born by the movements and have a healthy baby. 


\section{Objectives Of The Study:-}

1. To assess the existing knowledge of primigravidae regarding self assessment of daily fetal movement count.

2. To evaluate the effectiveness of video assisted teaching on self assessment of daily fetal movement count.

3. To find the association between the post test knowledge scores and selected demographic variables.

\section{Material and Method:-}

The research design selected for the study was Pre-experimental, Single group pre-test and post-test design. The independent variable was video assisted Teaching on self assessment of daily fetal movement count (DFMC) and the dependent variable was post-test knowledge scores of primigravidae attending antenatal OPD.

The sample of this study comprised of 50 primigravidae attending antenatal OPD in Vanivilas Maternity hospital at, Bengaluru. Non probability purposive sampling technique was used to draw the samples of the study. The tool developed and used for the data collection was structured knowledge questionnaire. 11 experts validated the content validity of the tool and the tool was found to be reliable and feasible. The video assisted teaching consisted of various aspects on DFMC. The video assisted teaching was developed with a view to enhance the knowledge of primigravidae.

Pilot study was conducted at Jayanagar General Hospital, Bengaluru. As a part of the major study, tool proved to be comprehensible, feasible and acceptable. Data collection procedure for main study began after obtaining permission from the concerned authorities of Vanivilas maternity hospital, Bengaluru. The investigator personally explained the need to the respondents and assured them of confidentiality of their responses.

The pre-test was administered followed by a video assisted teaching; post-test was administered 7 days after teaching by using the same questionnaire used in the pre-test.

The data gathered were analysed and interpreted according to objectives. Descriptive statistics mean and standard deviation were used. And inferential statistics paired ' $t$ ' test and chi-square were included to test the hypotheses at different levels of significance and the data obtained are presented in the graphical form.

\section{Results:-}

Section 1:- Aspect wise pre-test mean knowledge scores of respondents on self assessment of daily fetal movement count (dfmc)

Table 1:-

\begin{tabular}{|l|l|l|l|l|l|}
\hline $\begin{array}{l}\text { SL. } \\
\text { NO }\end{array}$ & Area wise & No. of items & Mean & S.D & Mean\% \\
\hline 1 & Perception of fetal movements & 6 & 2.2200 & 0.76372 & 37.00 \\
\hline 2 & $\begin{array}{l}\text { Importance of fetal movement } \\
\text { counting }\end{array}$ & 5 & 1.8400 & 0.79179 & 36.80 \\
\hline 3 & $\begin{array}{l}\text { Conditions for decreased fetal } \\
\text { movements }\end{array}$ & 4 & 1.4600 & 0.76158 & 36.50 \\
\hline 4 & Self assessment of fetal movement & 6 & 1.5000 & 0.76265 & 25.00 \\
\hline 5 & Home coping skills & 5 & 1.2800 & 0.70102 & 25.60 \\
\hline & Overall knowledge & 26 & 8.3000 & 1.78714 & 31.92 \\
\hline
\end{tabular}

Table 1 : reveals that the aspect wise pre-test knowledge of respondents regarding self assessment of daily fetal movement count. The highest mean \% was seen in the aspect perception of fetal movement counting $37 \%$, importance of fetal movement counting with 36.80, conditions for decreased fetal movements with $36.50 \%$, home coping skills with mean $\%$ of $25.60 \%$ and the lowest mean $25 \%$ was seen in the self assessment of fetal movement.

Section 1a:- Aspect wise post -test mean knowledge scores of respondents on self assessment of daily fetal movement count 
Table 1 a:-

\begin{tabular}{|l|l|l|l|l|l|}
\hline $\begin{array}{l}\text { SL. } \\
\text { NO }\end{array}$ & Area wise & No. of items & Mean & S.D & Mean \% \\
\hline 1 & Perception of fetal movements & 6 & 4.8000 & 0.60609 & 80.00 \\
\hline 2 & Importance of fetal movement counting & 5 & 4.2800 & 0.67128 & 85.60 \\
\hline 3 & Conditions for decreased fetal movements & 4 & 3.3800 & 0.66670 & 84.50 \\
\hline 4 & Self assessment of fetal movement & 6 & 4.9400 & 0.71171 & 82.33 \\
\hline 5 & Home coping skills & 5 & 4.2800 & 0.67128 & 85.60 \\
\hline & Overall knowledge & 26 & 21.6800 & 1.09619 & 83.38 \\
\hline
\end{tabular}

Table 1a: reveals that the aspect wise post-test knowledge of respondents regarding self assessment of daily fetal movement count. The highest mean $\%$ was seen in the aspect of importance of fetal movement counting and home coping skills with $85.60 \%$, followed by conditions for decreased fetal movements $84.50 \%$ followed by self assessment of daily fetal movement with $82.33 \%$ and the lowest score mean in the aspect perception of fetal movements with $80 \%$ was seen in knowledge regarding self assessment of daily fetal movement count.

Section 2:-Over all pre -test and post- test mean knowledge on self assessment of daily fetal movement count

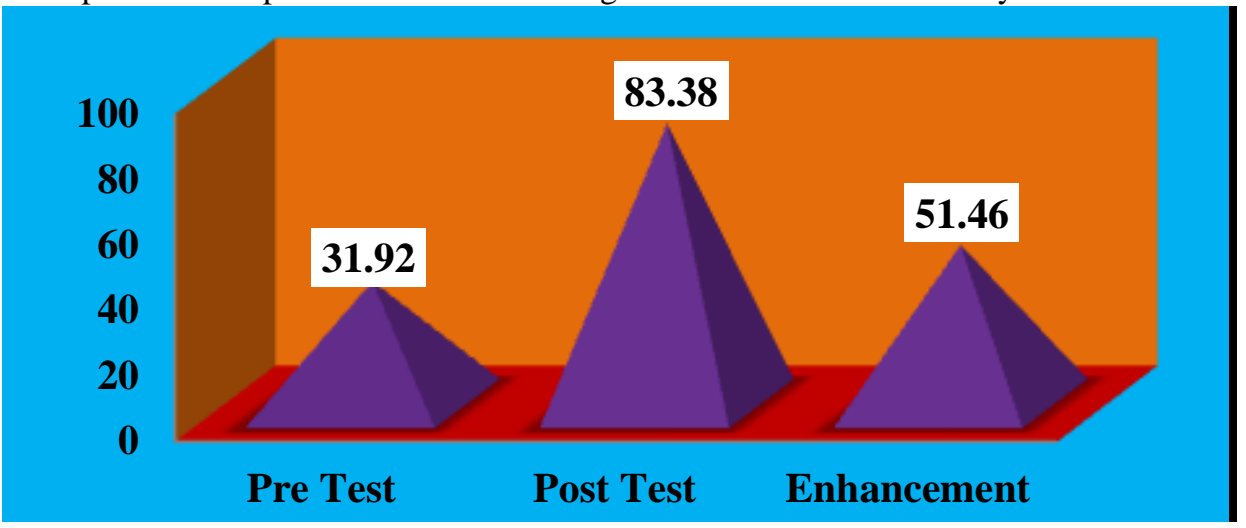

Figure 1:- Depicts that pre-test mean knowledge score was $31.92 \%$ and post-test value was $83.38 \%$ with enhancement of $51.46 \%$, with paired " $t$ " test value of $19.57 *$. It is significant at $5 \%$ level.

Section 3:- Aspect wise mean pre-test and post-test knowledge scores of respondents on self assessment of daily fetal movement count (dfmc) comparison of pre test and post test knowledge scores (paired t test).

Table 2

\begin{tabular}{|l|l|l|l|l|l|l|l|}
\hline \multirow{2}{*}{ Aspects of knowledge } & \multicolumn{2}{|l|}{ Pre test } & \multicolumn{2}{l|}{ Post test } & t value & DF & $\begin{array}{l}\text { P value } \\
\text { Inference }\end{array}$ \\
\cline { 2 - 8 } & Mean & SD & Mean & SD & & \\
\hline Perception of fetal movements & 37.00 & 0.76372 & 80.00 & 0.60609 & 17.349 & 49 & $\mathrm{P}<0.05^{*}$ \\
\hline $\begin{array}{l}\text { Importance of fetal movement } \\
\text { counting }\end{array}$ & 36.80 & 0.79179 & 85.60 & 0.67128 & 19.510 & 49 & $\mathrm{P}<0.05^{*}$ \\
\hline $\begin{array}{l}\text { Conditions for decreased fetal } \\
\text { movements }\end{array}$ & 36.50 & 0.76158 & 84.50 & 0.66670 & 17.444 & 49 & $\mathrm{P}<0.05^{*}$ \\
\hline $\begin{array}{l}\text { Self assessment of fetal } \\
\text { movement }\end{array}$ & 25.00 & 0.76265 & 82.33 & 0.71171 & 26.174 & 49 & $\mathrm{P}<0.05^{*}$ \\
\hline $\begin{array}{l}\text { Home coping skills } \\
\text { Overall knowledge }\end{array}$ & 25.60 & 0.70102 & 85.60 & 0.67128 & 24.089 & 49 & $\mathrm{P}<0.05^{*}$ \\
\hline
\end{tabular}

Table 2:- reveals overall mean score in the pre-test was $31.92 \%$ and $83.38 \%$ in the post-test with an enhancement of $51.46 \%$. The statistical paired ' $t$ ' test indicates the enhancement in the mean knowledge scores is found to be significant at 0.05 level for all the aspect under the study 
Section 4:- Association between post knowledge with selected demographic variables Table 3

\begin{tabular}{|c|c|c|c|c|c|c|}
\hline & \multicolumn{5}{|c|}{ Overall Knowledge } \\
\hline & & \multicolumn{2}{|c|}{ Median and below } & \multicolumn{2}{|c|}{ Above median } & \multirow{2}{*}{$\begin{array}{l}\text { Chi } \\
\text { square }\end{array}$} \\
\hline & & $\mathbf{N}$ & $\%$ & $\mathbf{N}$ & $\%$ & \\
\hline \multirow[t]{4}{*}{ Age in years } & 19-23yrs & 23 & 65.7 & 12 & 34.3 & $6.767 *$ \\
\hline & 24-28yrs & 15 & 100.0 & 0 & 0.0 & $\mathrm{DF}=1$ \\
\hline & 29-33yrs & 0 & 0.0 & 0 & 0.0 & \\
\hline & $34-38 \mathrm{yrs}$ & 0 & 0.0 & 0 & 0.0 & \\
\hline \multirow[t]{5}{*}{ Educational status } & No formal education & 4 & 80.0 & 1 & 20.0 & $5.467^{\mathrm{NS}}$ \\
\hline & Primary school & 9 & 69.2 & 4 & 30.8 & $\mathrm{DF}=3$ \\
\hline & High school & 13 & 65.0 & 7 & 35.0 & \\
\hline & Secondary education & 12 & 100.0 & 0 & 0.0 & \\
\hline & Graduation and above & 0 & 0.0 & 0 & 0.0 & \\
\hline \multirow{5}{*}{ Occupation } & Home maker & 15 & 60.0 & 10 & 40.0 & $7.019 *$ \\
\hline & Coolie & 12 & 92.3 & 1 & 7.7 & $\mathrm{DF}=2$ \\
\hline & Private employee & 11 & 91.7 & 1 & 8.3 & \\
\hline & Government employee & 0 & 0.0 & 0 & 0.0 & \\
\hline & Self employed / Business & 0 & 0.0 & 0 & 0.0 & \\
\hline \multirow{4}{*}{$\begin{array}{l}\text { Monthly income in } \\
\text { Rupees }\end{array}$} & $5,000-10,000$ & 24 & 68.6 & 11 & 31.4 & $3.530^{\mathrm{NS}}$ \\
\hline & $10,001-15,000$ & 14 & 93.3 & 1 & 6.7 & $\mathrm{DF}=1$ \\
\hline & $15,001-20,000$ & 0 & 0.0 & 0 & 0.0 & \\
\hline & 20,001 and above & 0 & 0.0 & 0 & 0.0 & \\
\hline \multirow{4}{*}{$\begin{array}{l}\text { Years of married life } \\
\text { in years }\end{array}$} & $00-05$ & 38 & 76.0 & 12 & 24.0 & ----- \\
\hline & $06-10$ & 0 & 0.0 & 0 & 0.0 & \\
\hline & $11-15$ & 0 & 0.0 & 0 & 0.0 & \\
\hline & $16-20$ & 0 & 0.0 & 0 & 0.0 & \\
\hline \multirow{3}{*}{$\begin{array}{l}\text { Gestational age in } \\
\text { weeks }\end{array}$} & 24-28 weeks & 14 & 77.8 & 4 & 22.2 & $0.049^{\mathrm{NS}}$ \\
\hline & 29-33 weeks & 24 & 75.0 & 8 & 25.0 & $\mathrm{DF}=1$ \\
\hline & 34-38 weeks & 0 & 0.0 & 0 & 0.0 & \\
\hline \multirow[t]{2}{*}{ Type of family } & Nuclear & 31 & 77.5 & 9 & 22.5 & $0.247^{\mathrm{NS}}$ \\
\hline & Joint & 7 & 70.0 & 3 & 30.0 & $\mathrm{DF}=1$ \\
\hline
\end{tabular}

Table 3:- Revealed there was significant association between post-test knowledge scores and selected sociodemographic variables such as age in years, occupational status at 0.05 levels. The findings of the study revealed that there was no significant association between post-test knowledge score and few selected socio-demographic variables such as educational status, monthly income, years of married life, gestational age in weeks, type of family and source of information at 0.05 levels.

\section{Discussion:-}

The pre-test knowledge score among majority of primigravidae were found to be moderate and post-test knowledge score is enhanced.There was significant enhancement in knowledge of primigravidae attending antenatal OPD after conducting video assisted Teaching on self assessment of daily fetal movement count (DFMC).There was significant association between post-test knowledge scores and selected socio-demographic variables such as age in years, occupational status at 0.05 levels. The findings of the study revealed that there was no significant association between post-test knowledge score and few selected socio-demographic variables such as educational status, monthly income, years of married life, gestational age in weeks, type of family and source of information at 0.05 levels. 


\section{Conclusion:-}

The nursing implications are as follows.

\section{Nursing Practice:-}

The study shows various degree of deficiency in the knowledge regarding Self assessment of daily fetal movement count (DFMC), among primigravidae, for this nurses need to have adequate knowledge regarding Self assessment of daily fetal movement count (DFMC) to enhance the knowledge of primigravidae attending antenatal OPD.By providing adequate knowledge to Primigravidae the health care providers can motivate the mothers to count the daily fetal movement count to identify and prevent the fetal complications during the pregnancy.

Nursing Education:Nursing personnel should give education to the primigravidae attending the antenatal OPD regarding Self assessment of daily fetal movement count (DFMC). As a nurse educator, there are abundant opportunities for nursing professionals to educate the student nurses who are in the clinical posting, and primigravidae attending antenatal OPD regarding Self assessment of daily fetal movement count (DFMC).Nurse educators can use the findings of this study to upgrade her knowledge and find the other different strategies which are simple so that it will be easy to educate the student nurses as well as the pregnant mothers.As a nurse educator, there are abundant opportunities for nursing professionals to educate the student nurses, as well as common lay persons regarding Self assessment of daily fetal movement count (DFMC).

\section{Nursing Administration:-}

The nurse administrator should arrange induction programme for staff nurses working in the Obstetrics and Gynecological unit. This will help the nurse administrator to prepare adequate learning materials for giving health education in the colleges as well as in the hospitals. This will help the nurse administrator to emphasis and encourage the nurses to use different strategies to educate staffnurses, student nurses and pregnant mothers regarding Self assessment of daily fetal movement count (DFMC).Nursing personnel should be prepared to take leadership role in educating the student nurses, and the novice nurses regarding Self assessment of daily fetal movement count (DFMC) whereby they can educate the mothers in the clinical area or community when they encounter the pregnancy.

\section{Nursing research:-}

The study will motivate the beginning researchers to conduct same study with different variables on a large scale.Nurses should come forward to take up unsolved questions in the field and nursing fraternity. The public and private agencies should also encourage researcher in the field through materials and funds.

\section{Limitations of the study:-}

1. The study is limited only to primigravidae attending antenatal OPD in Vanivilas Maternity Hospital at Bengaluru.

2. The study did not use control group.

3. Only a single domain that is knowledge is considered in the present study.

4. The sample for the study was limited to 50 primigravidae attending antenatal OPD.

\section{Recommendations:-}

On the basis of the findings of the study following recommendations have been made:

1. A replication of present study can be conducted with a larger population.

2. A similar study can be conducted in different settings at Hospitals in rural areas and urban areas and then due results can be compared.

3. Manuals and information booklets may be developed to enhance knowledge on Self assessment of daily fetal movement count (DFMC).

4. Videos can be pre installed if the facility of Televisions are available in the hospitals so that it enhances the knowledge on Self assessment of daily fetal movement count (DFMC). 


\section{Summary:-}

This chapter dealth with the findings, conclusion, nursing implication, limitation and recommendations of the study.

\section{References:-}

1. Laurie Davis. Daily movement counting- A valuable assessment tool. Journal of Nurse Midwifery 1987JanFeb;32(1):11-19. Available from: http://www.science direct.com/.

2. http://iresearch.World bank.org/Povcal Net. Life Style lounge.http//i love india.com.

3. Ministry Of Health and Family Welfare Government of India. National Family Health Survey (NFHS-3) 20052006. Available from: http://www.measuredhs.com.

4. Current Scientific research conferences about decreased fetal movement. Available from: http://www.infoplease.com/images/03/atlas.

5. Light a candle.The global indicator to reduce the still birth.Available from:http://www.who/ucf/0786.com.

6. Shirley Fischer, Judith Townsend Fullerton, Lois Trecise. Fetal movement and fetal outcome in a low risk population. Journal of Nurse Midwifery 1981;26:24-30. Available from: http://www.science direct.com/science?-ob=ArticleURL.

7. Helen Varney, Jan M.Kriebs Kasolyn, L.Gegor"Varney's" Text Book of Midwifery, Fourth edition. All India publishers and Distributors Regd. Page No. 632-635.

8. Adele Pillitteri “Maternal Child Nursing” Third Edition, Lippincot Publication Page no.183,184,199,264.

9. Lippincot. Manual of Nursing Practice. $8^{\text {th }}$ ed. India: Lippincot Publications; 2000. 